\title{
O SIGNO E O HOMEM: UMA BREVE REFLEXÃO
}

\author{
Richard da Silva ${ }^{1}$ \\ Marcia Bianco ${ }^{2}$
}

\begin{abstract}
Resumo: O presente resumo é resultado de um estudo que analisou questões relativas à linguagem humana, cujas teorias são diversas. Buscou-se, por meio da metodologia de cunho bibliográfico, verificar reflexões em torno do que se diz acerca da origem da linguagem, verificando definições apontadas por alguns autores a respeito das significações de termos, especialmente relevantes no estudo da linguagem, dos diferentes signos linguísticos. Objetivou-se verificar as divergências dos estudiosos conforme os enfoques, desde uma perspectiva teológica, filosófica, científica, tecnológica, entre outras. Chauí, Peirce e Saussure discutem questões relativas à linguagem, partindo do seu surgimento e trazendo significativas contribuições quanto a sua sistemática de signos e sinais carregados de expressões, valores e sentimentos. Assim, constatou-se que pensar a linguagem implica, antes, entender que existe uma grande diferença entre o homem e os outros animais, sendo que somente o primeiro é capaz do logos. Saussure defende que um signo linguístico é a unidade básica da língua. Toda língua é um sistema completo de signos e, por sua vez, todo signo possui dupla face: o significante e o significado.
\end{abstract}

Palavras-chave: Linguagem; Sígnos Linguísticos; Língua.

\section{THE SIGN AND THE MAN: A BRIEF REFLECTION}

Abstract: This abstract is the result of a study that analyzed issues related to human language, whose theories are diverse. We sought, through a bibliographical methodology, to verify reflections about what is said about the origin of the language, checking definitions pointed out by some authors regarding the meanings of terms, especially relevant in the study of language, different linguistic signs . The objective was to verify the divergences of the students according to the approaches, from a theological, philosophical, scientific and technological perspective, among others. Chauí, Peirce and Saussure discuss issues related to language, starting from its emergence and bringing significant contributions as to its systematics of signs and signs loaded with expressions, values and feelings. Thus, it was found that thinking the language implies, rather, to understand that there is a great difference between the man and the other animals, being that only the first one is capable of the logos. Saussure argues that a linguistic sign is the basic unit of language. Every language is a complete system of signs and, in turn,

\footnotetext{
${ }^{1}$ Graduado em Letras (Unisul). Especialista em Linguística de Língua Portuguesa (Unisul). Mestre em TESOL- Teaching English for Speakers of Other Languages (NMSU - USA). E-mail: richard@unibave.net.

${ }^{2}$ Graduada em Letras (Unisul). Especialista em Interdisciplinaridade (FUCAP). Mestre em Ciências da Linguagem (Unisul). E-mail: marcia.bianco@yahoo.com.br
} 


\section{Universidade do Extremo Sul Catarinense \\ Revista Ibero-Americana de Humanidades, Ciências e \\ Educação \\ unesc

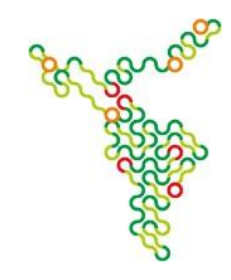

every sign has a double face: the signifier and the meaning.

Keywords: Language; Linguistic signs; Language.

\section{Introdução}

Tratar de questões relativas à linguagem humana não é assunto nem um pouco simples; pelo contrário teorias diversas têm-se preocupado em nortear discussões nesse sentido. O que se quer aqui nesse estudo, todavia, não é aprofundar nenhuma teoria em especial, mas simplesmente encaminhar uma reflexão em torno do que se diz acerca da origem da linguagem, passando por uma definição já estabelecida, para daí então, chegarse ao objetivo o qual é pensar a linguagem pelo viés da semiótica, verificando definições apontadas por alguns autores a respeito das significações de termos especialmente relevantes no estudo da linguagem, dos diferentes signos linguísticos e também dos símbolos.

Quando se busca estudar sobre a origem da linguagem, percebe-se haver uma diversidade de pontos de vista. E mais: esses pontos de vista divergem conforme os enfoques em questão. Assim ter-se-ia, numa perspectiva divina, por exemplo, que foi Deus quem concedeu ao homem o dom da linguagem. Diferentemente se defenderia a origem da linguagem por outros pontos de vista como o científico, o sociológico, etc.

Segundo Chauí (2004), pelo viés da filosofia, ao se perguntar pela origem da linguagem, quatro tipos de respostas apareceriam, a primeira seria a linguagem que nasce por imitação dos sons, caracterizando-se como onomatopeia, ou seja, aquela que imita os sons dos animais e/ou da natureza. A segunda ressalta o aprendizado por imitação dos gestos, os quais indicam um sentido, esta somente mais tarde passaria a acompanhar também os sons. Como terceira origem da linguagem tem-se as necessidades, de comer, de se proteger de animais ou dos próprios homens, entre outros, onde por meio de um vocabulário elementar o qual foi se transformando e adaptando com o passar do tempo tornou-se uma língua. O quarto e último item é a linguagem que nasce das emoções, do grito, do riso, do choro e demais manifestações.

Essas diferentes maneiras de a filosofia explicar a origem da linguagem não devem ser vistas como excludentes, pelo contrário, Chauí (2004) ainda ressalta que possivelmente a linguagem tenha nascido dos mais diversos modos de expressão.

Se há encaminhamentos diferentes para se falar sobre a origem da linguagem, há 


\section{Universidade do Extremo Sul Catarinense \\ Revista Ibero-Americana de Humanidades, Ciências e \\ Educação \\ unesc

também para se definir linguagem. Interessa, aqui, fazer referência a seguinte definição do mesmo autor: "a linguagem é um sistema de signos ou sinais usados para indicar coisas, para a comunicação entre pessoas e para a expressão de ideias, valores e sentimentos". Percebe-se que tal definição, além de carregar em si uma complexidade, abre espaço para outras reflexões importantes. Por exemplo: que é signo (ou sinal)? Que espécie de signos existem? Qual a importância dos signos para a vida em sociedade? Que teóricos se ocuparam de estudar os signos? Há uma teoria voltada a estudar os signos?

Pensar a linguagem por esse viés implica, antes, entender que se existe uma grande diferença entre o homem e os outros animais, esta manifesta-se especialmente por dois importantes fatores relativos à linguagem: um, o homem destaca-se entre os animais que fazem uso de signos; outro, somente o homem é capaz do logos. Para melhor explorar essa questão, é preciso pensar, primeiramente, nos signos utilizados pelo homem. Seja na fala, na escrita, na arte, nos instrumentos de sinalização humana, nos dispositivos de teste, nos diagnósticos médicos, eles alcançam elaboração e complexidade. Morris (1976, p. 9) defende que "A civilização humana depende dos sinais e sistemas de signos e a mente humana é inseparável do funcionamento dos sinais, se é que não deva identificar-se com este funcionamento".

Com Aristóteles (apud Chauí, 2004), de outro lado, há de se considerar que:

[...] somente o homem é um "animal político", isto é, social e cívico, porque somente ele é dotado de linguagem. Os outros animais (...) possuem voz ("phoné") e, com ela, exprimem dor e prazer, mas o homem possui a palavra ("logos") e, com ela, exprime o bom e o mau, o justo e o injusto. Exprimir e possuir em comum esses valores é o que torna possível a vida social e política e, dela, somente os homens são capazes (p.147).

É indiscutível, portanto, a importância que tem sido dada ao estudo dos signos. Nos últimos tempos, não só linguistas, como também, filósofos, psicólogos, biólogos, antropólogos, sociólogos e psicopatologistas têm buscado inteirar-se de questões relativas aos signos.

O termo signo, que deriva etimologicamente do grego sêmeion (signo) e sema (sinal), tem sua história já nos escritos de Platão sobre a linguagem. Entretanto, a noção de signo não é limitada à linguagem. Mais do que apresentar definições de signo, necessário se faz compreender a importância e a presença dos signos nas atividades que implicam relações humanas. A propósito, Peirce (1997) ressalta: 


\section{Universidade do Extremo Sul Catarinense Revista lbero-Americana de Humanidades, Ciências e Educação

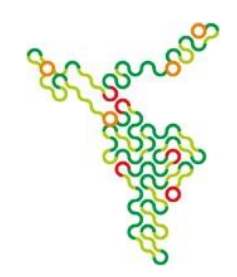

Não é possível qualquer ato de cognição que não seja determinado por uma outra cognição prévia, na medida em que todo pensamento implica a interpretação ou representação de alguma coisa. Todo pensamento ou conceito está inextricavelmente ligado às funções de representação, não sendo capaz de se interpretar a si mesmo. A interpretação somente pode realizar-se através do signo (In os Pensadores, 1980).

Acrescentem-se ao que já foi dito as palavras esclarecedoras de Santaella (1994) a qual diz que signo é uma coisa que representa outra coisa, ou seja é uma representatividade de algo, portanto signo não é o objeto, apenas o representa de certa forma. Para exemplificar Santaella aponta o termo casa, que dá forma escrita, fotografada, desenhada ou um filme são signos do objeto casa, porém não são a própria casa. Isso se refere ao processo racional que se cria na mente do interprete.

Existem diferentes tipos de signos, que podem ser verbal e não verbal. Isso equivale a pensar que há signos linguísticos e signos não-linguísticos. Enquanto Peirce (1997) debruçava-se sobre os estudos dos signos não linguísticos, Saussure (2004) dedicava-se aos linguísticos. Esses dois teóricos a quem se fez menção têm importância significativa para a Ciência Semiótica Moderna.

Peirce (2004) divide esses signos em três espécies principais: ícone, índices e símbolos. Quanto ao ícone assim esclarece: "O ícone constitui um tipo de signo em que o significado e o significante apresentam uma semelhança de fato. O desenho de um animal seria um exemplo de ícone; o desenho significa o animal, simplesmente porque se parece com ele".

A ideia de ícone talvez fique mais clara quando se busca a etimologia: Ícon, elemento grego que significa imagem. Nesse sentido, pode-se dizer que maquetes, estátuas, fotografias, caricaturas são todos signos icônicos. Também merecem destaque como ícones os cartuns e as charges que se referem a pessoas.

É importante uma referência ao que Valente (1997) menciona acerca do emprego do termo ícone, o qual tomou maior proporção ao ser usado pela imprensa. Diz ele:

O termo 'ícone' vem tendo um uso especial pela imprensa brasileira. Nas áreas cultural e política, o termo tem sido empregado com o sentido de 'imagem simbólica de uma época, de uma manifestação artística ou de um contexto sociopolítico. O 'ícone' vem a ser, então, o 'representante mais expressivo'. Com tal significação, podem-se encontrar passagens como: 'John Lennon é um ícone dos anos 60'; 'Getúlio Vargas é um ícone da vida política brasileira'. 


\section{Universidade do Extremo Sul Catarinense \\ Revista Ibero-Americana de Humanidades, Ciências e \\ Educação \\ unesc

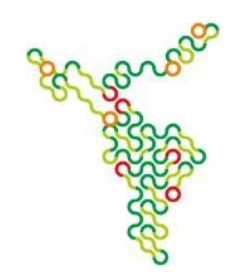

Nos chamados cadernos de cultura dos principais jornais brasileiros e também nas revistas semanais.

Com relação a índice, na visão de Peirce (2004), é sustentado pelo mesmo que este é um signo que não se parece ao objeto significado, porém indica-o casualmente, é um sintoma dele, ainda cita como exemplo que um furo de bala, por exemplo, é o índice de um tiro, logo a fumaça é índice de fogo.

Quanto ao símbolo, para Valente (1997) tem caráter convencionado pelo uso, ou seja, existe uma ligação entre significante e significado, sendo assim, cita a "cruz", como sendo um símbolo do cristianismo, logo a "bandeira branca" como símbolo da paz. Peirce (2004) também justifica seu pensamento citando:

O símbolo, ao contrário, opera segundo uma contiguidade instituída, ou seja, depende da adoção de uma regra de uso. As bandeiras constituem símbolos das nações; entre as bandeiras e as nações não há qualquer relação causal necessária, trata-se apenas de convenção. A quase totalidade da linguagem usual, falada e escrita, é de natureza simbólica (In Os Pensadores, 1980, p. X).

Em um comparativo entre as reflexões dos dois autores anteriormente citados pôde-se perceber que seguem a mesma linha de raciocínio. No entanto outros autores têm ideias divergentes a esses com relação ao significado de símbolo. Fazendo menção as cores ou aos animais, Valente (1997) ressalta que o uso simbólico dos mesmos é feito por influência político-cultural, exemplificando a questão dos animais, tem-se o "touro" simbolizando a força, "a raposa" demonstrando a esperteza, a "tartaruga" como símbolo de lentidão, entre outros mais. Em sentido mais amplo pode-se usar termos com referência internacional, como a "pomba", indicativo de paz.

Existem símbolos que constituem valores culturais nacionais ou regionais, nesse grupo se atribuem as logomarcas, bandeiras, logotipos, escudos, entre outros.

É Saussure quem defende que um signo linguístico é a unidade básica da língua. Toda língua é um sistema completo de signos. Todo signo possui dupla face: o significante e o significado. O significante é o aspecto concreto do signo, é a sua realidade material, ou imagem acústica. O que constitui o significante é o conjunto sonoro, fônico, que torna o signo audível ou legível. O significado é o aspecto imaterial, conceitual do signo e que nos remete à determinada representação mental evocada pelo significante.

Segundo Lopes (1995), ao incluir o significado na concepção do signo linguístico, Saussure põe o sistema dos sentidos dentro do sistema linguístico. E é isso que confere à Semântica um lugar no interior da Linguística. Importa lembrar, ainda com Lopes, que 


\section{Universidade do Extremo Sul Catarinense Revista Ibero-Americana de Humanidades, Ciências e Educação

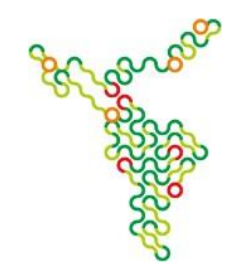

antes da publicação da obra de Saussure (C L G) era comum chamar-se signo apenas à imagem acústica, com total menosprezo do significado.

Os signos ainda se baseando nas palavras de Lopes (1995), tem ligação direta com as relações humanas.

Assim como a relação entre o homem e o mundo vem mediatizada pelo pensamento, a relação entre um homem e outro homem, dentro de uma sociedade, vem mediatizada pelos signos. Para que o pensamento transite de uma para outra subjetividade, deve ele formalizar-se em signos. Os signos são, por um lado, suportes exteriores e materiais da comunicação entre as pessoas e, por outro lado, são o meio pelo qual se exprime a relação entre o homem e o mundo que o cerca (Lopes, 1995, p.16).

Algumas características são estipuladas por Saussure para designar signo:

o signo é arbitrário: Isso quer dizer que não há uma ligação natural entre significante e o significado. Isso quer dizer que quando lemos uma palavra como "maçã", a combinação de sons existente a partir das letras usadas para formar a palavra $(\mathrm{M}+\mathrm{A}+$ Ç+ Ã) não designa o objeto, oi a coisa propriamente dita, é necessário a leitura e logo relacionar o significante e o significado pela convenção a ela destinada no determinado local.

É interessante perceber que o signo tem um valor relativo na língua, assim, logo que uma determinada coisa recebe um nome, esse te convenciona tornando-se impossível trocá-lo, pode-se exemplificar verificando que "maçã" não pode ser chamada de “abacaxi”, pois o sentido não é o mesmo.

o signo é representativo, simbólico: O signo é o resultado da junção entre significante e conceito, não entre uma coisa e seu nome.

a linearidade do signo: o elementos os quais constituem o signo são combinados, logo, obedecem uma sequência, que por sua vez se estrutura para poder ser compreendida, ocupando uma posição determinada. Saussure (2004) discorre que o pensamento está atrelado às palavras, partindo desse princípio cria bases para a teoria das formas, configurando-se mais tarde em Estruturalismo linguístico. A linearidade discute as regras as quais são dispostas as palavras dependendo da Língua a qual é usada, considerando-se nesta contextualização a Língua Portuguesa, é possível exemplificar destacando que o artigo sempre antecede o substantivo, não sendo aceito pelas normas o contrário disso.

Variação do signo: significados universais como por exemplo palavras como pai ou mãe apresentam significantes diferentes dependendo da língua usada. 
Universidade do Extremo Sul Catarinense

Revista Ibero-Americana de Humanidades, Ciências e

Educação

Unesc Produção e democratização do conhecimento na lbero-América

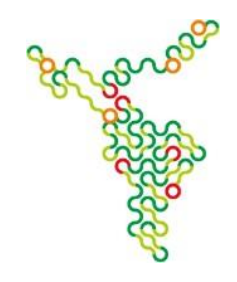

\begin{tabular}{|l|l|l|}
\hline Português & Espanhol & Inglês \\
\hline mãe/ pai & madre/padre & mother/ father \\
\hline
\end{tabular}

Não se pode esquecer que existem significantes os quais possuem significados diferentes, é o caso das palavras pelo, manga, macaco, tênis, vela, entre outras. Ainda, ressalta-se a importância de refletir, após as explanações anteriores, e considerar que os sistemas de signos estendem-se para além da forma verbal, ou seja, entende-se que existem muitas formas de comunicação não verbal, alguns usando o próprio corpo, como o sorriso, um gesto, o aperto de mão, ou vários outros meios expressam uma comunicação. Esta pode ser pelas roupas que são usadas, os acessórios, entre outros itens, os quais nos mostram que os signos são representados de várias maneiras, porém para compreendê-los melhor é necessário um aprofundamento no assunto.

\section{CONSIDERAÇÕES FINAIS}

A linguagem verbal não está dissociada da não-verbal; nesse sentido, Saussure e Pierce contribuem para as reflexões pertinentes a essa esfera. $\mathrm{O}$ debate a respeito dos conceitos acerca da linguagem ocorre por haver divergência/contribuição entre os diversos autores, o conhecimento a respeito tem aumentado no último século, porém é pouco divulgado. Saussurre (2004) nomeia de linguística interna os estudos referenciados à fala ou à escrita, no entanto é comum chamar de estudos linguísticos a todas análises referentes à linguagem. Pode-se então perceber que a própria definiçãa do termo linguagem se diferencia dos demais estudiosos, trazendo à tona diversas teorias a respeito.

A cada definição analisada se constata que, independente do século em que a linguagem se tornou objeto de estudo, muitos acréscimos foram sendo feitos neste âmbito, deixando claro que existe uma vasta complexidade a respeito, sobre a qual merece maior empenho no desenvolvimento de pesquisas. Pode-se assim valorizar essas teorias como pertinentes e relevantes sobre o estudo da linguagem, e, sobretudo, possibilitando novos indicadores para futuras análises.

\section{REFERÊNCIAS}

CHAUÍ, Marilena de Sousa. Convite à filosofia. 6. ed. São Paulo: Ática, 1997.

LOPES, E. Fundamentos da Linguística contemporânea. 14.ed. São Paulo: Cultrix, 
Universidade do Extremo Sul Catarinense

Revista lbero-Americana de Humanidades, Ciências e

Educação

UneSC Produção e democratização do conhecimento na lbero-América

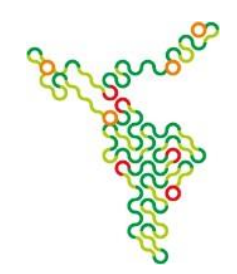

1995.

MORRIS, Charles W.. Fundamentos da teoria dos signos. Rio de Janeiro: Eldorado Tijuca, 1976.

SANTAELlA, Lúcia. Semiótica Aplicada. São Paulo: Pioneira Thomson Learning, 2002.

SAUSSURE, Ferdinand de. Curso de lingüística geral. 26. ed. São Paulo: Cultrix, 2004.

VALENTE, André. A linguagem nossa de cada dia. Petrópolis: Vozes, 1997. 